Brief Report

\title{
Reliability and Repeatability of the Instrument for the Assessment of Stress in Nursing Students (ASNS)
}

\author{
Marta Elena Losa-Iglesias *(D), Raquel Jiménez-Fernández, Almudena Alameda-Cuesta, \\ Maria Gema Cid-Exposito $\mathbb{D}$, Rocío Rodriguez-Vazquez and Ricardo Becerro-de-Bengoa-Vallejo $\mathbb{D}$ \\ Facultad de Ciencias de la Salud, Universidad Rey Juan Carlos, Avenida de Atenas, 28040 Madrid, Spain; \\ raquel.jimenez@urjc.es (R.J.-F.); almudena.alameda@urjc.es (A.A.-C.); gema.cid@urjc.es (M.G.C.-E.); \\ rocio.vazquez@urjc.es (R.R.-V.); ribebeva@ucm.es (R.B.-d.-B.-V.) \\ * Correspondence: marta.losa@urjc.es
}

Received: 7 September 2019; Accepted: 20 September 2019; Published: 24 September 2019

\begin{abstract}
Background and objectives: Stress in nursing students is a very common experience, especially when they face clinical practice. The aims of this study were to perform a transcultural adaptation and to examine the reliability and repeatability of the Instrument for the Assessment of Stress in Nursing Students for a Spanish population. Methods: A test-retest analysis was carried out in two face-to-face sessions with the students with a lapse of 10 days between the two sessions. A cross-sectional descriptive study was carried out between the months of May and June 2018. Sixty-four nursing students were recruited with a consecutive sampling method that targeted individuals in the freshman class. Results: A good internal consistency was shown for the total score $(\alpha=0.8861)$ and for each of the six domains. The test-retest reliability, using the Wilcoxon paired test, was not significant, indicating no differences between the total scores or the domain scores $(p \geq 0.05)$. Finally, Bland and Altman plots of visual distributions did not show differences between the total scores and the domain scores. Conclusion: The Instrument for the Assessment of Stress in Nursing Students was shown to be a reliable tool for measuring stress factors among Spanish nursing students.
\end{abstract}

Keywords: stress; nursing students; questionnaire

\section{Introduction}

The presence of stress in students of all levels and ages is a reality in universities around the world [1]. The medical sciences have been reported as one of the branches of knowledge in which students experience high levels of stress [2,3].

Nursing students have a heavy load of theoretical and practical teaching hours with a high level of emotional demand [4]. This was demonstrated in several studies that found that stress among nursing students was very high, resulting in morbidity and psychological exhaustion $[5,6]$.

There are not many validated measurement instruments to quantify stress in nursing students. One of those that is validated and that shows very good psychometric properties is the Instrument for the Assessment of Stress in Nursing Students (ASNS). The instrument is composed of 30 items grouped into six domains: performance of practical activities; professional communication; time management; environment; professional education; and theoretical activities. A factor analysis of the instrument's psychometric properties confirmed that the conceptual model was acceptable, resulting in Cronbach's alphas ranging from 0.71 to 0.87 [7].

This instrument has been used in previous studies, and the results were very useful for assessing the stress factors among nursing students, which led to good results [8-11]. 
The ASNS had not been adapted to the Spanish language or validated in a Spanish population. Therefore, this study aimed to perform a transcultural adaptation and test the reliability and repeatability of the Instrument for the Assessment of Stress in Nursing Students in a Spanish population.

\section{Materials and Methods}

\subsection{Study Design}

A cross-sectional descriptive study was carried out between the months of May and June 2018. Transcultural adaptation and reliability and a repeatability assessment were carried out using the ASNS with nursing students who were recruited with a consecutive sampling method from the freshman class at the University of Rey Juan Carlos (URJC) (Madrid, Spain). The ages of the participants ranged from 19 to 33 years old. The exclusion criteria were prior history working in medical settings, such as a nursing assistant position or any kind of work at a hospital, day care center, or similar institution; refusal to sign the informed consent form; inability to understand the instructions for completing the test; and being of a nationality other than Spanish [7] .

This research was approved by the Ethics Committee of the Hospital Universitario Clínico San Carlos (Madrid, Spain), number 18/278-E, on 6 June 2018.

\subsection{Translation Procedure}

The internationally recommended forward/reverse translation protocol was applied for the translation, transcultural adaptation, and validation of the constructs [12,13]. Finally, the proofread version of the ASNS was composed of the same items ( 30 items) and Likert scale that were used in the original version.

\subsection{Test-Retest Reliability and Sample Size}

Test-retest was carried out during two face-to-face sessions with the students with a lapse of 10 days between the two sessions. In addition to the ASNS items, socio-demographic data such as age and gender were requested in the session. Participants were recruited from the Faculty of Health Sciences of URJC, Spain. Considering the correlation with a CCI of 0.40 and a $95 \%$ confidence interval (CI) for a two-tailed test, an $\alpha$ error of 0.05 , and a desired analysis power of $80 \%$ (error $\beta=20 \%$ ), the final sample included at least 53 participants.

\subsection{Statistical Analysis}

Independent Student $t$-tests were performed to determine whether there were statistically significant differences when a normal distribution was shown. Considering the total score and each domain score, internal consistency and reliability were analyzed using the intraclass correlation coefficient (ICC) and Cronbach's alpha ( $\alpha$ ) with a confidence interval of $95 \%(95 \% \mathrm{CI})$. For the statistical analysis, we used a bidirectional random effects model (2.1), single measures, absolute agreement, and ICC to express reliability. In addition, a Wilcoxon paired test was applied to test the systematic differences between the original test and the new test. A Bland and Altman plot was also analyzed to assess agreement and heteroscedasticity [14] .

\section{Results}

\subsection{Translation}

The final sample that completed the two questionnaires comprised of 64 individuals: 56 women and 8 men. The age of the students ranged from 18 to 33 with a mean age of $19 \pm 2.18$ years old. The forward translations were performed with no discrepancies between the two versions. 


\subsection{Reliability and Repeatability}

The Cronbach's alpha for the total score shows a good internal consistency in the post-test, $\alpha=$ 0.8861 with a $95 \%$ lower confidence limit of 0.8467 ; the ICC with a $95 \%$ confidence interval was 0.5162 (0.2036-0.7061). Additionally, we found a very good internal consistency in all the domains of the questionnaire: the performance of practical activities had a Cronbach's alpha of 0.8602; professional communication, $\alpha=0.8785$; time management, $\alpha=0.876$; environment, $\alpha=0.9063$; professional education, $\alpha=0.864$; and finally, theoretical activities, $\alpha=0.8646$.

Table 1 shows the results of the concordance of the test-retest questionnaire by the 30 items and 6 domains.

Table 1. Analysis of intraclass correlation coefficient (ICC) between pre- and post-test of the adapted Assessment of Stress in Nursing Students (ASNS).

\begin{tabular}{|c|c|}
\hline Items/Domains & ICC \\
\hline Domain: Performance of practical activities & $0.984(0.973-0.990)$ \\
\hline Item 5: New situations one may experience in clinical practice & $0.941(0.903-0.964)$ \\
\hline Item 7: Environment of the training clinical ward & $0.949(0.916-0.969)$ \\
\hline Item 9: Fear of making mistakes while assisting patients & $0.988(0.981-0.993)$ \\
\hline Item 21: Feeling of not having enough knowledge for the practical test & $0.996(0.993-0.997)$ \\
\hline Item 4: Performing the general assistance procedures & $1(1-1)$ \\
\hline Item 12: Performing certain assistance procedures & $1(1-1)$ \\
\hline Domain: Professional communication & $0.933(0.890-0.959)$ \\
\hline Item 6: Communication with the other professionals at the training ward & $0.959(0.932-0.975)$ \\
\hline Item 8: Communication with professionals of other sectors at the training ward & $0.963(0.939-0.977)$ \\
\hline $\begin{array}{l}\text { Item 16: Perception of difficulties regarding relationships with other nursing } \\
\text { professionals }\end{array}$ & $0.958(0.931-0.975)$ \\
\hline Item 20: Identification of contradictory attitudes in the other professionals & $966(0.944-0.979)$ \\
\hline Domain: Time management & $0.989(0.982-0.993)$ \\
\hline Item 18: Little time to spend with family members & $0.988(0.980-0.993)$ \\
\hline Item 3: Reduced social interactions because of feelings of loneliness & $1(1-1)$ \\
\hline Item 26: Lack of leisure time & $0.987(0.978-0.992)$ \\
\hline Item 30: Lack of time to rest & $0.968(0.946-0.980)$ \\
\hline Item 23: Time demanded by the professor to prepare extra class activities & $0.996(0.994-0.998)$ \\
\hline Domain: Environment & $0.989(0.982-0.993)$ \\
\hline Item 11: Distance between school and residence & $0.969(0.949-0.981)$ \\
\hline Item 29: Public transportation used to go to the training place & $0.984(0.974-0.990)$ \\
\hline Item 22: Public transportation used to go to school & $0.994(0.991-0.997)$ \\
\hline Item 24: Distance between most training places and residences & $0.978(0.964-0.987)$ \\
\hline Domain: Professional education & $0.995(0.993-0.997)$ \\
\hline Item 1: Concerns about professional future & $0.965(0.974-0.990)$ \\
\hline $\begin{array}{l}\text { Item 15: Similarities between situations experienced during the training process and } \\
\text { those that may be experienced during professional life }\end{array}$ & $1(1-1)$ \\
\hline Item 17: Thinking of situations that may be experienced during professional life & $0.978(0.964-0.987)$ \\
\hline Item 19: Perceptions of professional responsibility while doing the training program & $0.971(0.952-0.982)$ \\
\hline Item 25: Experiencing activities in the training field as a nursing student & $1(1-1)$ \\
\hline Item 27: Perceptions of the theoretical knowledge acquired during the course & $0.984(0.973-0.990)$ \\
\hline Domain: Theoretical activities & $0.993(0.988-0.995)$ \\
\hline Item 10: Format of method used to assess theoretical content & $0.988(0.980-0.993)$ \\
\hline Item 13: Feelings of insecurity or fear while taking theoretical exams & $0.994(0.990-0.996)$ \\
\hline Item 14: Level of difficulty of extra class assignments & $0.995(0.991-0.997)$ \\
\hline Item 2: Obligation to do extra class assignments & $0.988(0.981-0.993)$ \\
\hline Item 28: Understanding the theoretical and practical content taught in the classroom & $0.982(0.971-0.989)$ \\
\hline
\end{tabular}

The test-retest reliability, using the Wilcoxon paired test, was not significant (ICC 95\%), indicating that there were no systematic differences in the total scores of the questionnaires $(p>0.05)$. For the 
domains scores, statistically significant differences were not found in the mean (SD) difference between test and retest for any of the domains.

The 95\% limit of agreements and Bland and Altman plots did not show changes or relevant differences from test to retest for the total scores (Figure 1) or for the six different domains of the questionnaire.

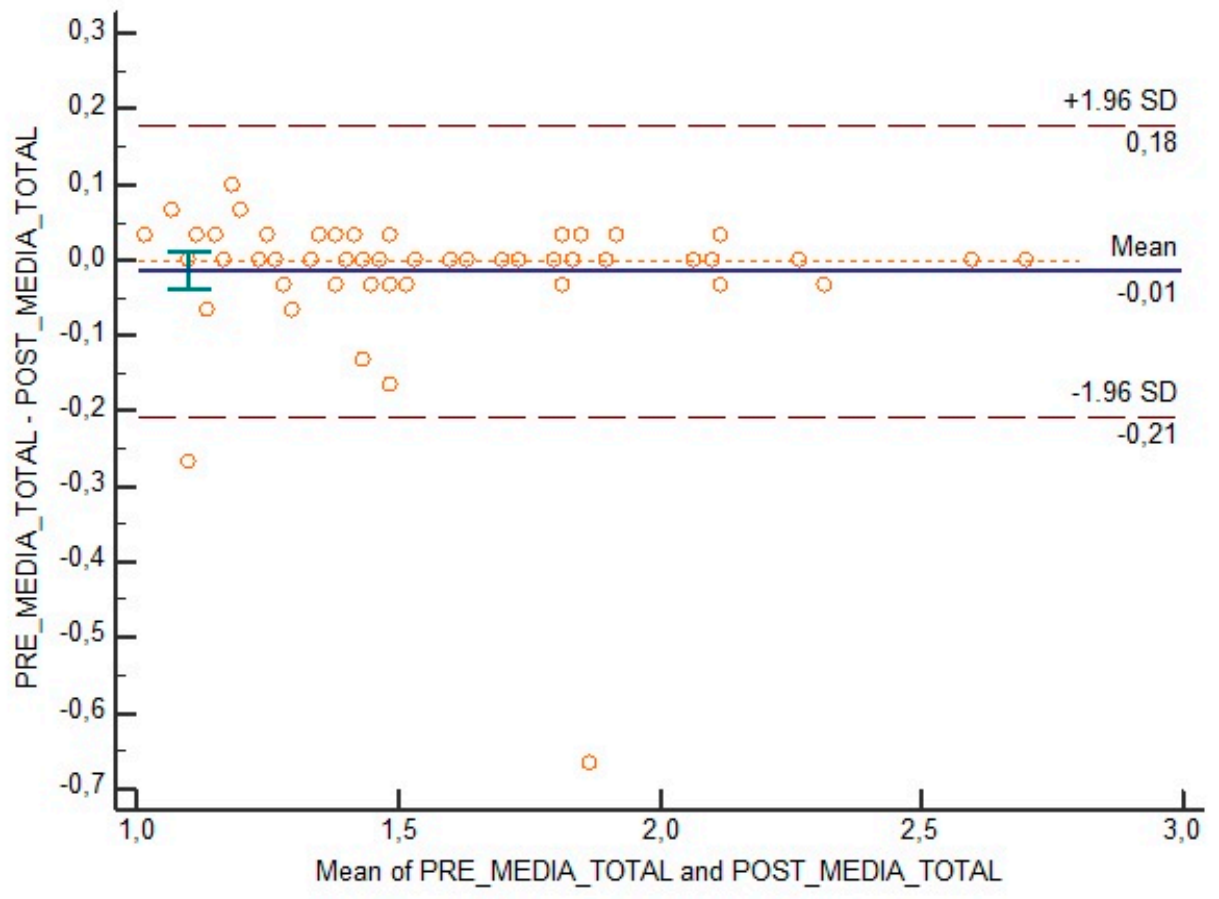

Figure 1. Bland and Altman plot for total items of adapted ASNS.

\section{Discussion}

According to Wild [13], the guidelines for the process of cross-cultural adaptation of self-reported measures, and by following George and Mallery's [15] recommendations to evaluate Cronbach's alpha coefficients, the adapted ASNS for a Spanish population is a reliable and valid questionnaire for measuring stress in nursing students. Our results are comparable to and slightly better than those obtained with the original validation of the questionnaire by Costa \& Polak [7] , as we found higher Cronbach's alpha values for the total test scores and for all the domains and better ICC values by domain and item. This could be because our sample was similar to the original validation sample on age and sex variables, though our sample came from exclusively freshman students with no previous experience in clinical settings, and this aspect can have a positive influence since there is no sample contamination or bias [16] .

The Spanish version of the ASNS was shown to be a valid and reliable tool with very good internal consistency for evaluating stress in nursing students due to performance of practical activities (0.8602), professional communication (0.8785), time management (0.876), environment (0.9063), professional education (0.864), and theoretical activities (0.8646). The questionnaire shows excellent reproducibility; all the $p$ values from the Wilcoxon paired test were not statistically significant.

In general, the Bland and Altman method shows whether there are differences between the tests (the pre- and post-test) to check the reproducibility of the results of the test and whether the differences are systematic or random.

Comparing our reliability data $(\alpha=0.8861)$ with those of other tools used to measure nursing stress in freshman students, we found results similar to those of Sheu et al. [17] with an $\alpha$ of 0.89 , Shaban et al. [18] with an $\alpha$ of 0.87, and Karabacak et al. [19] with an $\alpha$ of 0.70 . 
The validation of a tool to measure stress in nursing students in Spain was also performed by Zupiria et al. [20], and these authors reported that the KEZKAK questionnaire had an $\alpha$ of 0.95 . This value is higher than that of our questionnaire. In this study, the researchers included nursing students in all years of study, so this value cannot be compared with our value. The value obtained by Zupiria et al. [20] is in accordance with that obtained in another study with a heterogeneous sample conducted by Chen and Hung [21] which obtained an $\alpha$ of 0.91 . Finally, age and sex were not considered in this validation due to the sample size.

\section{Conclusions}

The Instrument for the Assessment of Stress in Nursing Students (ASNS) for measuring stress factors among nursing students was shown to be a reliable tool for use with the Spanish students and may be used to obtain total scores or domain scores in further studies.

Author Contributions: Conceptualization, M.E.L.-I. and R.B.-d.-B.-V.; methodology, M.E.L.-I. and R.B.-d.-B.-V.; software, M.E.L.-I. and R.B.-d.-B.-V.; validation, M.G.C.-E. and R.J.-F.; formal analysis, M.E.L.-I. and R.B.-d.-B.-V.; investigation, M.E.L.-I.; resources, M.E.L.-I.; data curation, M.E.L.-I. and R.J.-F. and A.A.-C. and M.G.C.E; writing-original draft preparation, M.E.L.-I. and R.B.-d.-B.-V.; writing-review and editing, M.G.C.-E. and R.J.-F. and A.A.-C. and R.R.-V.; visualization, R.R.-V.; supervision, R.B.-d.-B.-V.; project administration, M.E.L.-I.; funding acquisition, M.E.L.-I. and R.B.-d.-B.-V.

Funding: This research received no external funding.

Acknowledgments: We thank Costa, the author of the Instrument for the Assessment of Stress in Nursing Students, for her support in carrying out this research and the translation and posterior validation.

Conflicts of Interest: The authors declare no conflict of interest.

\section{References}

1. Ranjita, M.; Castillo, L. Academic Stress Among College Students: Comparison of American and International Students. Int. J. Stress Manag. 2004, 11, 132-148. [CrossRef]

2. Waghachavare, V.B.; Dhumale, G.B.; Kadam, Y.R.; Gore, A.D. A Study of Stress among Students of Professional Colleges from an Urban area in India. Sultan Qaboos Univ. Med J. 2013, 13, 429-436. Available online: https://europepmc.org/articles/pmc3749028 (accessed on 21 January 2018). [CrossRef] [PubMed]

3. Ticona Benavente, S.B.; Siqueira Costa, A.L. Physiological and emotional responses to stress in nursing students: An integrative review of scientific literature. Acta Paul. Enferm. 2011, 24, 571-576. [CrossRef]

4. Lapeña-Moñux, Y.R.; Cibanal-Juan, L.; Orts-Cortés, M.I.; Maciá-Soler, M.L.; Palacios-Ceña, D. Nurses' experiences working with nursing students in a hospital: A phenomenological enquiry. Rev. Lat. Am. Enferm. 2016, 24, e2788. [CrossRef] [PubMed]

5. Watson, R.; Deary, I.; Thompson, D.; Li, G. A study of stress and burnout in nursing students in Hong Kong: A questionnaire survey. Int. J. Nurs. Stud. 2008, 45, 1534-1542. [CrossRef] [PubMed]

6. $\quad$ Cheung, T.; Wong, S.Y.; Wong, K.Y.; Law, L.Y.; Ng, K.; Tong, M.T.; Yip, P.S. Depression, anxiety and symptoms of stress among baccalaureate nursing students in hong kong: A cross-sectional study. Int. J. Environ. Res. Public Health 2016, 13, 779. [CrossRef] [PubMed]

7. Costa, A.L.S.; Polak, C. Construction and validation of an instrument for the assessment of stress among nursing students. Rev. Esc. Enferm. USP 2009, 43, 1017-1026. [CrossRef]

8. Costa, A.L.S.; de Azevedo Guido, L.; Da Silva, R.M.; Lopes, L.F.D.; Mussi, F.C. Stress intensity of a nursing students regarding to biosocial and academic characteristics-A cross-sectional study. J. Nurs. Educ. Pract. 2013, 4, 29. [CrossRef]

9. Hirata Soares, M.; Santana Oliveira, F. The relation between alcohol, tobacco and stress in nursing students. SMAD Revista Electrónica Salud Mental Alcohol Drogas 2013, 9, 88-94. Available online: http://pepsic.bvsalud. org/pdf/smad/v9n2/07.pdf (accessed on 1 February 2018).

10. Ticona Benavente, S.B.; Silva, R.M.D.; Higashi, A.B.; Guido, L.D.A.; Costa, A.L.S. Influence of stress factors and socio-demographic characteristics on the sleep quality of nursing students. Rev. Esc. Enferm. USP 2014, 48, 514-520. [CrossRef] [PubMed] 
11. Fernandes Pereira, F.G.; Nunes Caldini, L.; Di Ciero Miranda, M.; Áfio Caetano, J. Assessment of stress in the inclusion of nursing students in hospital practice. Investig. Educ. Enferm. 2014, 32, 430-437. [CrossRef] [PubMed]

12. Beaton, D.E.; Bombardier, C.; Guillemin, F.; Ferraz, M.B. Guidelines for the process of cross-cultural adaptation of self-report measures. Spine 2000, 25, 3186-3191. [CrossRef] [PubMed]

13. Wild, D.; Grove, A.; Martin, M.; Eremenco, S.; McElroy, S.; Verjee-Lorenz, A.; Erikson, P. Principles of good practice for the translation and cultural adaptation process for patient-reported outcomes (PRO) measures: Report of the ISPOR Task Force for Translation and Cultural Adaptation. Value Health 2005, 8, 94-104. [CrossRef] [PubMed]

14. Bland, J.M.; Altman, D.G. Statistical methods for assessing agreement between two methods of clinical measurement. Lancet 1986, 1, 307-310. [CrossRef]

15. George, D.; Mallery, P. SPSS for Windows Step by Step: A Simple Guide and Reference, 4th ed.; 11.0 update; Allyn \& Bacon: Boston, MA, USA, 2003.

16. Grimes, D.A.; Schulz, K.F. Bias and causal associations in observational research. Lancet 2002, 359, $248-252$. [CrossRef]

17. Sheu, S.; Lin, H.S.; Hwang, S.L. Perceived stress and physio-psycho-social status of nursing students during their initial period of clinical practice: The effect of coping behaviors. Int. J. Nurs. Stud. 2002, 39, 165-175. [CrossRef]

18. Shaban, I.A.; Khater, W.A.; Akhu-Zaheya, L.M. Undergraduate nursing students' stress sources and coping behaviours during their initial period of clinical training: A Jordanian perspective. Nurse Educ. Pract. 2012, 12, 204-209. [CrossRef] [PubMed]

19. Karabacak, Ü.; Uslusoy, E.; Şenturan, L.; Alpar, Ş.E.; Yavuz, D. First day in clinical practice: Evaluating stress of nursing students and their ways to cope with it. Healthmed 2012, 6, 596-602. Available online: https://s3.amazonaws.com/academia.edu.documents/49124786/Cystex_2012.pdf?AWSAccessKeyId= AKIAIWOWYYGZ2Y53UL3A\&Expires=1547895847\&Signature=ujdSbXcUwXOq1ZuKKdxxkoaTYwI\% 3D\&response-content-disposition=inline\%3B\%20filename\%3DCystex_2012.pdf.pdf\#page=260 (accessed on 1 February 2018).

20. Zupiria, G.X.; Uranga, I.M.J.; Alberdi, E.M.J.; Barandiaran, L.M. KEZKAZ: (bilingual questionnaire of nursing students' stressors in clinical practice). Gac. Sanit. 2003, 17, 37-51. (In Spanish) [CrossRef]

21. Chen, Y.W.; Hung, C.H. Predictors of Taiwanese baccalaureate nursing students' physio-psycho-social responses during clinical practicum. Nurse Educ. Today 2013, 34, 73-77. [CrossRef] [PubMed] 